\title{
Antagonism by Chloramphenicol of Carbon Tetrachloride Hepatotoxicity
}

\section{Examination of Microsomal Cytochrome P-450 and Lipid Peroxidation ${ }^{I}$}

\author{
Elizabeth D. Dolci and Michael J. Brabec \\ Department of Environmental and Industrial Health, School of Public Health, \\ The University of Michigan, Ann Arbor, Michigan 48109
}

Received April 25, 1977, and in revised form August 8, 1977

\begin{abstract}
Administration of chloramphenicol early in $\mathrm{CCl}_{t}$ intoxication prevents lipid peroxidation of endoplasmic reticulum membranes. Conversely, a sulfamoyl analog, Tevenel, was ineffective in preventing the lipoperoxidative process. Likewise, in an in vitro microsomal system chloramphenicol inhibited a lipid peroxidation process and Tevenel did not. However, both compounds bind to cytochrome P-450. Chloramphenicol did not maintain cytochrome $P-450$ levels after $\mathrm{CCl}_{4}$ administration nor did it depress cytochrome P-450 levels in untreated animals. The data obtained indicate that chloramphenicol may prevent lipid peroxidation either by inhibiting $\mathrm{CCl}_{4}$ metabolism or by acting as a free radical sequestering agent.
\end{abstract}

\section{INTRODUCTION}

It is now generally accepted that metabolism of $\mathrm{CCl}_{4}$ is essential in the pathogenesis of carbon tetrachloride-induced liver injury. Since the major stable products of $\mathrm{CCl}_{4}$ metabolism, $\mathrm{CO}_{2}$ and $\mathrm{CHCl}_{3}$, are relatively nontoxic, and since the $\mathrm{CCl}_{4}$ molecule itself must be cleaved before its toxicological potentiality can be expressed, it seems clear that events intimately associated with the cleavage of the $\mathrm{CCl}_{3}-\mathrm{Cl}$ bond must be responsible for initiating the pathological conscquences. Metabolism of $\mathrm{CCl}_{4}$ by the $\mathrm{MFO}^{2}$ system in the hepatic endoplasmic reticulum is postulated to result in homolytic cleavage of the carbon-chlorine bond, producing $\mathrm{CCl}_{3} \cdot$ and $\mathrm{Cl} \cdot$ free radicals. The disruption of cellular function is attributed to the reaction of $\mathrm{CCl}_{3}$. with either (1) membrane lipids promoting an autocatalytic peroxidative process and destroying the membranc (Rccknagel, 1967; Glende, 1972b) or (2) neighboring proteins and other macromolecules altering their cellular function (Diáz Goméz et al., 1973; Castro et al., 1975). However, studies of anaerobic metabolism of $\mathrm{CCl}_{4}$ in vitro indicate that peroxidation of microsomal lipids appears to be obligatory for loss of microsomal enzyme

1 This work was supported by Public Health Grant No. RO1 ES 01024 from the National Institute of Environmental Health Sciences. Elizabeth D. Dolci received trainee support from Environmental Health Sciences Research Training Grant 5 TO1 ES 00138 from NIEHS.

2 Abbreviations used: D-CAPS, D-threo-chloramphenicol, succinyl sodium salt; D-CAP, Doptical isomer of threo-chloramphenicol; L-CAP, L-isomer of threo-chloramphenicol; ip, intraperitoneally; DMSO, dimethyl sulfoxide; EDTA, ethylenediaminetetraacetate; ER, endoplasmic reticulum; MFO, mixed function oxidase. 
activity, supporting this route as the initial cellular lesion (Glende et al., 1976).

Insight into the mechanism of action of $\mathrm{CCl}_{4}$ has been facilitated through use of agents which prevent development of the necrosis associated with $\mathrm{CCl}_{4}$ administration. Recently chloramphenicol (D-CAP), a broad-spectrum antibiotic, has been shown to function as an antagonist of hepatotoxicity, particularly the mitochondrial damage, induced by $\mathrm{CCl}_{4}$ (Huyen and Banaschak, 1973; Brabec and Bernstein, 1975; Brabec et al., 1976). The protective action of D-CAP does not appear to be associated with its antibiotic activity, nor with its inhibition of mitochondrial protein synthesis. Tevenel, a structural analog, has similar antibiotic properties but does not protect from $\mathrm{CCl}_{4}$ toxicity. Conversely, an optical isomer of chloramphenicol (L-CAP) which is inactive as an antibiotic and as an inhibitor of mitochondrial protein synthesis does protect mitochondria from $\mathrm{CCl}_{4}$ induced mitochondrial damage (Brabec and Bernstein, 1975; Brabec et al., 1976). In addition, interaction of chloramphenicol with the microsomal MFO system has been reported (Grogan et al., 1972; Huyen et al., 1974; Dixon and Fouts, 1962).

In light of the action of D-CAP on $\mathrm{CCl}_{4}$-induced liver injury, a study was conducted to determine whether D-CAP's protective effect was exerted at the site of ER injury during early stages of $\mathrm{CCl}_{4}$ intoxication and, if so, what parameters of ER damage were altered. A further aim was to reveal those processes, now marked by their sensitivity to interruption by D-CAP, that lead to mitochondrial damage.

\section{METHODS}

Adult ( 250 to $350-\mathrm{g}$ ) male CFN strain rats were maintained on a commercial diet of rat chow and water ad libitum. Carbon tetrachloride was administered ip without a carrier at selected doses. The succinyl derivative of chloramphenicol, dissolved in water, was administered ip at $100 \mathrm{mg} / \mathrm{kg}$ body weight, while D-CAP and Tevenel were dissolved in propylene glycol or DMSO. Unless otherwise noted, $\mathrm{CCl}_{4}$ was administered followed immediately by D-CAP, D-CAPS, or Tevenel.

Microsomes were prepared by differential centrifugation of a $10 \%$ liver homogenate in an isolation medium containing $0.25 M$ sucrose, $10 \mathrm{mM}$ Tris, $10 \mathrm{mM}$ $\mathrm{KCl}$, and $1 \mathrm{mM}$ EDTA ( $\mathrm{pH} 7.0$ ). Mitochondria, nuclei, and cell debris were removed by centrifugation at $8800 \mathrm{gav}_{\mathrm{a}} \times 10 \mathrm{~min}$. The supernatant fraction was then centrifuged at $103,000 \mathrm{~g}_{\mathrm{av}} \times 60 \mathrm{~min}$ in a Spinco Model $\mathrm{L}$ ultracentrifuge.

Microsomal cytochrome P-450 content was determined by the method of Omura and Sato (1967). Animals were sacrificed by decapitation 15 and $20 \mathrm{hr}$ after administration of $\mathrm{CCl}_{4}(1.2 \mathrm{ml} / \mathrm{kg})$ and $\mathrm{D}$-CAPS. Microsomal protein was diluted to a concentration of $1 \mathrm{mg} / \mathrm{ml}$ in a buffer containing $0.15 \mathrm{M}$ Tris, and $25 \mathrm{mM} \mathrm{KCl}$, pH 7.5. Activity was measured using the split-beam mode of an Aminco DW-2 UV-VIS spectrophotometer.

Chloramphenicol interaction with hepatic microsomal cytochrome $P-450$ was analyzed by spectral binding studies. The ability of the drug to displace carbon monoxide from reduced P-450 was ascertained by the method described by Schenkman et al. (1967). Liver microsomes were diluted in a $25 \mathrm{mM} \mathrm{KCl}$ and $0.15 \mathrm{M}$ Tris buffer, $\mathrm{pH} 7.5$, to a protein concentration of $2.5 \mathrm{mg} / \mathrm{ml}$. Livers were perfused with isolation medium prior to fractionation. 
Binding studies with hexobarbital were carried out by following the spectral change between 420 and $500 \mathrm{~nm}$ as described by Schenkman et al. (1973). Liver microsomes were suspended in $0.2 \mathrm{M}$ sodium phosphate buffer, $\mathrm{pH} 7.5$, to a protein concentration of $2.6 \mathrm{mg} / \mathrm{ml}$. D-CAP or one of its analogs was added to both experimental (containing hexobarbital) and reference cuvettes in concentrations ranging from 0.25 to $5.0 \mathrm{mM}$. Microsomes used in the spectral binding experiments were prepared from rats pretreated with phenobarbital, $100 \mathrm{mg} /$ $\mathrm{kg}$ ip, for 5 days and sacrificed $48 \mathrm{hr}$ after the last injection.

The NADPH- and NADH-cytochrome $c$ reductase activities were measured in the presence of D-CAP or D-CAPS by the method described by Williams and Kamin (1962). The rate of reduction of cytochrome $c$ by NADH and NADPH was followed on a Beckman Gilford Model 2000 recording spectrophotometer.

Determination of lipid peroxidation in vivo was measured by conjugated diene formation as described by Recknagel and Goshal (1966). Animals were sacrificed $30 \mathrm{~min}$ after $\mathrm{CCl}_{4}(1.2 \mathrm{ml} / \mathrm{kg})$ administration. Lipids were extracted from $3.5 \mathrm{~g}$ of liver. Spectral scans were made against a methanol blank over the range of $220-300 \mathrm{~nm}$ on a Beckman DB spectrophotometer. Difference spectra were obtained by subtraction of scans of nonperoxidized lipid extracts.

Lipid peroxidation in vitro was measured by following $\mathrm{O}_{2}$ consumption in an Fe-ADP system as described by Ernster and Nordenbrand (1967). O.2 uptake was measured with a Clark electrode at $30^{\circ} \mathrm{C}$. D-CAP and Tevenel, dissolved in DMSO, were tested over concentrations ranging from 5 to $20 \mathrm{mM}$. The drug was added after a period of thermoequilibration of buffer and microsomes (2.6 $\mathrm{mg} / \mathrm{ml}$ of microsomal protein ). The reaction was initiated by addition of NADPFr.

Protein was analyzed by the Biuret method (Gornall et al., 1949).

Statistical analysis: Comparison of mean values was determined by one-way analysis of variance (Steele and Torrie, 1960). The significance of the difference between control and experimental means was performed by Dunnett's procedure (Dunnett, 1955). The significance of difference between treatments was determined by one degree of freedom contrasts (Steele and Torrie, 1960).

\section{RESULTS}

Two major ER-associated events which are integral with the development of $\mathrm{CCl}_{4}$-induced hepatotoxicity are loss of microsomal enzyme activity and the process of lipid peroxidation.

Using conjugated diene formation in lipids extracted from hepatic microsomes as an index of in vivo lipid peroxidation, we found a marked diene conjugation absorption after $30 \mathrm{~min}$ of poisoning by $\mathrm{CCl}_{4}$. Diene absorption in lipids from D-CAP-CCl ${ }_{4}$-treated rats was reduced by $71 \%$. Tevenel treatment did not alter the degree of $\mathrm{CCl}_{4}$-induced lipid peroxidation (Fig. 1).

Since chloranphenicol's effectiveness as a mitochondrial protective agent has been shown to be a function of time after delivery of $\mathrm{CCl}_{4}$ (Brabec et al., 1976) the ability of D-CAP to interrupt lipid peroxidation when administered $4.5 \mathrm{hr}$ after a single dose of $\mathrm{CCl}_{4}$ was tested. As illustrated in Fig. 2, D-CAP did not prevent the formation of conjugated dienes in membrane lipids of the ER when delivered at this time.

To further evaluate the effects of D-CAP on lipoperoxidation, studies of the process were conducted in vitro. D-CAP inhibited peroxide formation as mea- 


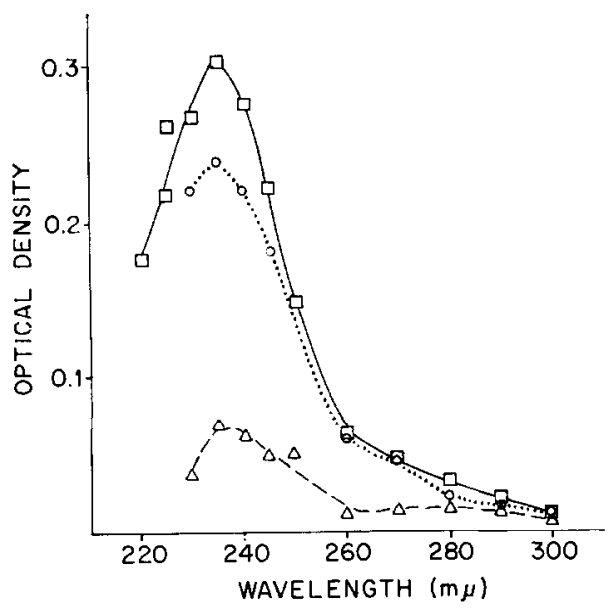

FIg. 1. Effect of chloramphenicol and Tevenel on $\mathrm{CCl}_{4}$-induced lipid peroxidation. Diene conjugation absorption of rat liver microsomal lipids. Rats were treated ip with $\mathrm{CCl}_{4}$ (1.2 $\mathrm{ml} / \mathrm{kg}), \mathrm{CCl}_{4}$ and $\mathrm{D}$-CAPS $(100 \mathrm{mg} / \mathrm{kg})$, or $\mathrm{CCl}_{4}$ and Tevenel $(100 \mathrm{mg} / \mathrm{kg}), 30 \mathrm{~min}$ prior to sacrifice. Lipids from $3.5 \mathrm{~g}$ of rat liver were extracted in a chloroform:methanol mixture (2:1). The recovered lipids were diluted in methanol to a concentration of $1 \mathrm{mg} / \mathrm{ml}$ and wavelength scans were determined against a methanol blank over the range of $220-300 \mathrm{~nm}$. Difference spectra were plotted: $(\longrightarrow) \mathrm{CCl}_{i} ;(\ldots \ldots)$ Tevenel $+\mathrm{CCl}_{t} ;(\ldots \ldots)$ D-CAPS $+\mathrm{CCl}_{4}$.

sured in an Fe-ADP-stimulated microsomal lipid peroxidation system (Fig. 3). In correlation with the experiments in vivo, Tevenel did not significantly affect the process of lipid peroxidation in vitro. D-CAP's effectiveness in inhibiting the peroxidative process in vitro displayed a requirement for an incubation period.

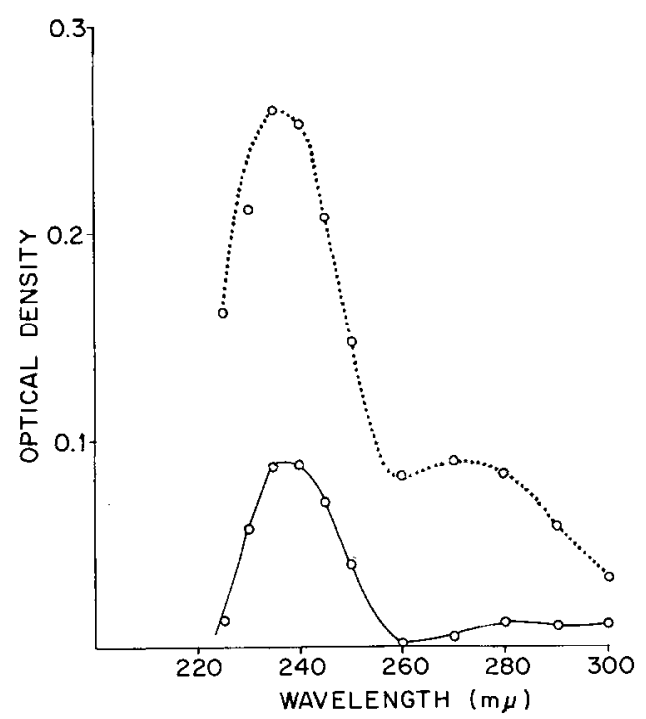

FIg. 2. Appearance of conjugated dienes in rat liver microsomal lipids following chloramphenicol treatment $5 \mathrm{hr}$ after $\mathrm{CCl}_{4}$ administration. Rats were treated ip with $\mathrm{CCl}_{4}(1.2 \mathrm{ml} / \mathrm{kg})$, followed $4.5 \mathrm{hr}$ later by D-CAPS ( $100 \mathrm{mg} / \mathrm{kg}$ ). Thirty minutes later the animals were sacrificed. Lipid extraction was performed as described in Fig. 1. (—) $\mathrm{CCl}_{1} ;(\ldots \ldots)$ D-CAPS and $\mathrm{CCl}_{4}$, 


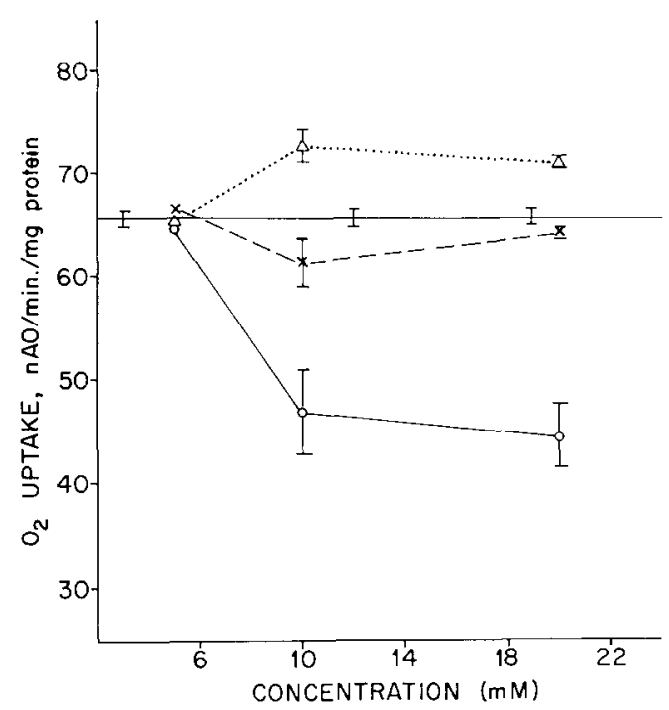

FIG. 3. Effect of chloramphenicol and Tevencl on in vitro lipid peroxidation as measured in an Fe-ADP-stimulated microsomal system. Liver microsomes were suspended in a $0.15 \mathrm{M}$ Tris, $25 \mathrm{mM} \mathrm{KCl}$ buffer, $\mathrm{pH} 7.5$, to a protein concentration of $2.6 \mathrm{mg} / \mathrm{ml}$. The drug or carrier was added prior to initiating the pcroxidative process. Results are expressed as means of the values $\pm S E$. DMSO values are equal to the volume in which the drug was suspended. The control is shown as a horizontal black line. (.....) Tevenel; (.....) DMSO; and (- D-CAP. Comparison of the 10 means was performed by a one-way analysis of variance. D-CAP at concentrations of 10 and $20 \mathrm{mM}$ was significantly different $(P<0.05)$ from the control using Dunnett's procedure.

D-CAP was ineffective as an inhibitor when administered after the peroxidative process had been initiated.

Since D-CAP decreases microsomal lipid peroxidation, it might likewise prevent the loss of cytochrome $P-450$ if these two events are causally related (Glende, 1972a). As illustrated in Table 1, D-CAP when administered with $\mathrm{CCl}_{4}$ did not significantly restore or prevent the loss of cytochrome $P-450$ at $15-20 \mathrm{hr}$ after exposure to $\mathrm{CCl}_{4}$. The levels of hepatic microsomal cytochrome $P-450$ in D-CAPprotected animals were not significantly different from those in $\mathrm{CCl}_{4}$-poisoned animals when compared at corresponding periods of exposure.

The decrease in lipid peroxidation caused by D-CAP suggests an effect on the metabolism of $\mathrm{CCl}_{4}$. This could be due to an interference with the electron flow from NADPH to cytochrome P-450. However, microsomal electron transport, as measured by the activity of NADPH-cytochrome $c$ reductase, was not altered in the presence of $\mathrm{D}$-CAP or D-CAPS (Table II).

The possible destruction of cytochrome $P-450$ by D-CAP within $5 \mathrm{hr}$ of $\mathrm{CCl}_{4}$ was investigated, as studies have shown that a decrease in the levels of cytochrome $P-450$ will reduce hepatotoxicity by $\mathrm{CCl}_{1}$ (Dambrauskas and Cornish, 1970; Seawright and McLean, 1967; Smuckler and Hutten, 1966). It was found that chloramphenicol did not depress cytochrome $P-450$ levels in rats when administered up to $6 \mathrm{hr}$ prior to sacrifice (control, $1.275 \times 10^{-3} \mu \mathrm{M} / \mathrm{mg}$ of protein; $6 \mathrm{hr}, 1.062 \times 10^{-3} \mu M / \mathrm{mg}$ of protein).

An interaction by D-CAP with cytochrome $P-450$ has been reported (Grogan et al., 1972; Huyen et al., 1974; Dixon and Fouts, 1962). To determine if this 
TABLE 1

Effect of Chloramphenicol and Carbon Tetrachloride on Cytochrome P-450

\begin{tabular}{cc}
\hline Treatment $^{a}$ & $\begin{array}{c}\text { Cytochrome P-450 } \\
(\mu M / \mathrm{mg} \text { of protein } / \mathrm{ml})\end{array}$ \\
\hline $\mathrm{CCl}^{b}$ & \\
$15 \mathrm{hr}(3)$ & $1.39 \times 10^{-4} \pm 0.12 \times 10^{-4}$ \\
$20 \mathrm{hr}(6)$ & $1.29 \times 10^{-4} \pm 0.47 \times 10^{-4}$ \\
$\mathrm{CCl}_{4}+\mathrm{D}-\mathrm{CAPS}^{b}$ & \\
$15 \mathrm{hr}(3)$ & $1.60 \times 10^{-4} \pm 0.19 \times 10^{-4}$ \\
$20 \mathrm{hr}(7)$ & $1.46 \times 10^{-4} \pm 0.56 \times 10^{-4}$ \\
Control $^{\circ}(8)$ & $3.70 \times 10^{-4} \pm 1.50 \times 10^{-4}$ \\
\hline
\end{tabular}

${ }^{a}$ Carbon tetrachloride $(1.2 \mathrm{ml} / \mathrm{kg})$ alone or with $\mathrm{D}-\mathrm{CAPS}(100 \mathrm{mg} / \mathrm{kg})$ was given ip to rats und the animals were sacrificed 15 or $20 \mathrm{hr}$ later. A liver suspension $(1.0 \mathrm{mg} / \mathrm{ml})$ was diluted in a $0.15 \mathrm{M}$ Tris, $25 \mathrm{mM} \mathrm{KCl}, \mathrm{pH} 7.5$, buffer. The number of rats used is in parentheses. Results are expressed as means of the values \pm SE. A one-way analysis of variance was used to compare the five groups. Five one degree of freedom contrasts determined the significance of difference between treatments.

${ }^{6}$ Differences between cytochrome $P-450$ levels in the $\mathrm{CCl}_{4}$-treated and $\mathrm{CCl}_{4}+{ }_{\mathrm{D}}$-CAPS-treated animals were not significant $(P>0.10)$. Interaction between drug and time was not significant $(P>0.10)$. Consequently, corresponding values at 15 and $20 \mathrm{hr}$ were pooled.

c The cytochrome $P-450$ levels in both the $\mathrm{CCl}_{4}$ - and $\mathrm{CCl}_{4}+{ }_{\mathrm{D}-\mathrm{CAPS}-t r e a t e d}$ animals were significantly different from the control $(P<0.001)$.

interaction could influence the activity of cytochrome $P-450$ and therefore $\mathrm{CCl}_{4}$ metabolism, spectral binding studies were done. When D-CAP was incubated with oxidized liver microsomes, neither Types I, II, nor reverse Type I spectra were observed. However, reaction with the heme moiety of the cytochrome $P-450$ molecule resulting in formation of a ferrihemochrome is characteristic of a Type II compound (Schenkman et al., 1967; Omura and Sato, 1964). As shown in Fig. 4, D-CAP and Tevenel both have the capacity to displace carbon monoxide from the reduced cytochrome $P-450$ hemochrome. Binding studies with hexobarbital revealed that both D-CAP and Tevenel were noncompetitive inhibitors of hexobarbital binding to the substrate site of cytochrome $P-450$ (Fig. 5). In this case, Tevenel was less effective than D-CAP.

\section{DISCUSSION}

Activation of carbon tetrachloride by the MFO system with homolytic cleavage of the molecule into $\mathrm{CCl}_{3}$. and $\mathrm{Cl} \cdot$ species is accepted by most investigators to be the mechanism which triggers the development of hepatonecrosis. Evidence supports the view that reactive free radicals initiate a lipoperoxidative process on organelle membranes as well as bind directly to macromolecules. Which reaction is the more lethal is not known. However, in vitro studies have shown that $\mathrm{CCl}_{4}$-induced loss of some microsomal enzyme activity depends on lipid peroxidation and not covalent binding of $\mathrm{CCl}_{4}$ cleavage products (Glende et al., 1976).

In our studies, chloramphenicol inhibited $\mathrm{CCl}_{4}$-induced lipid peroxidation in vivo and $\mathrm{Fe}-\mathrm{ADP}$-induced lipid peroxidation in vitro, while a structural analog, Tevenel, did not demonstrate any inhibition. Inhibition by D-CAP of lipid peroxidation may be explained by one of two mechanisms: (1) D-CAP 
TABLF, II

Effect of Chloramphenicol on NADPH- and NADH-

Cytochrome $c$ Reductase Activity ${ }^{a}$

\begin{tabular}{ccc}
\hline $\begin{array}{c}\text { D-CAP } \\
(\mathrm{m} M)\end{array}$ & $\begin{array}{c}\text { NADPH } \\
(\mu \text { moles of } \\
\text { cytochrome } c \\
\text { reduced } / \mathrm{min})\end{array}$ & $\begin{array}{c}\text { NADH } \\
(\mu \text { moles of } \\
\text { cytochrome } c \\
\text { reduced } / \mathrm{min})\end{array}$ \\
\hline- & $1.39 \times 10^{-3}$ & $1.53 \times 10^{-3}$ \\
7.5 & $1.15 \times 10^{-3}$ & $1.51 \times 10^{-3}$ \\
10.0 & $1.39 \times 10^{-3}$ & $1.69 \times 10^{-3}$ \\
\hline
\end{tabular}

${ }^{a}$ Liver microsomes were suspended in a $0.15 M$ Tris, $25 \mathrm{~m} M \mathrm{KCl}$ buffer, $\mathrm{pH} 7.5$. The cuvettes contained $34 \mu$ moles of cytochrome $c, 1 \mathrm{~m} M$ cyanide, and enzyme. Aliquots of $\mathrm{D}$-CAP ranging from 1 to $10 \mathrm{~m} M$ were added and the reaction was initiated by addition of $100 \mu$ moles of either $\mathrm{NADPH}$ or NAI)H. Reactions were run in duplicate.

could directly interrupt the peroxidative process by acting as a sequestering agent for $\mathrm{CCl}_{3} \cdot$ and $\mathrm{Cl} \cdot$ moleculcs, or (2) D-CAP could alter lipid peroxidation by blocking the activation of $\mathrm{CCl}_{4}$.

In support of (1), inhibition of electron transport by D-CAP in bacteria has been attributed to the formation of a benzoyl free radical which has the potential to function as an electron sink (Hansch et al., 1973). A benzoyl free radical may be generated by the microsomal MFO system. The inability of Tevenel to prevent lipid peroxidation could be due to the inability of the sulfamoyl group to stabilize a benzoyl free radical.
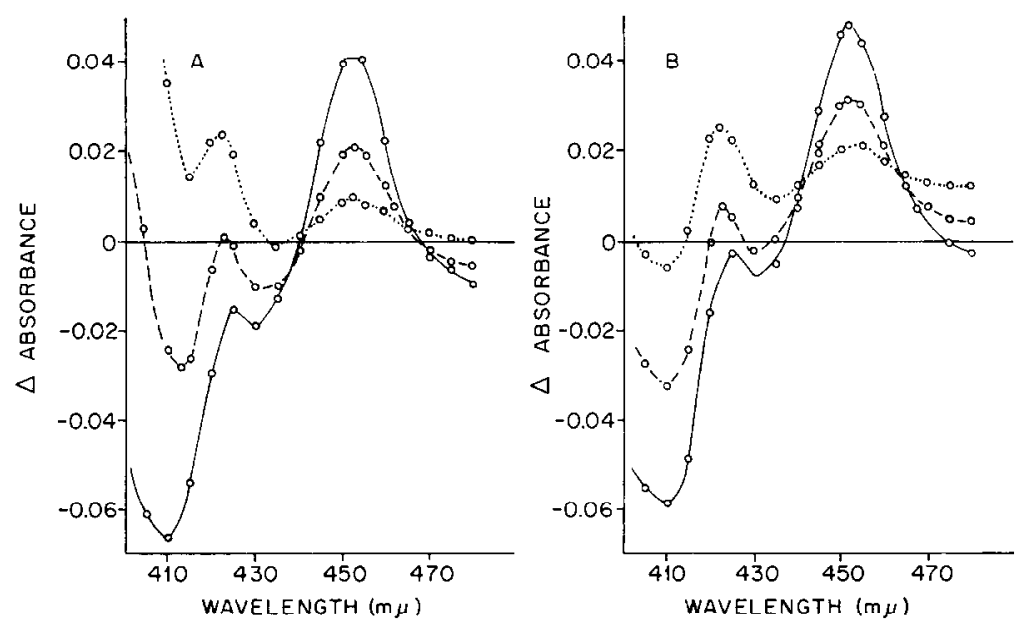

FIg. 4. The effects of D-CAP (A) and Tevenel (B) on the cytochrome P-450-CO complex. A microsomal suspension $(2.5 \mathrm{mg} / \mathrm{ml})$ was diluted in a $0.15 M$ Tris, $25 \mathrm{mM} \mathrm{KCl}$ buffer, $\mathrm{pH} 7.5$, and divided into two cuvettes. A baseline was scanned. The contents of the experimental cuvette were gassed with CO for 1 min and then $0.17 \mathrm{mM}$ NADPH was added to each cuvette (solid line). Aliquots of $D$-CAP or Tevenel in propylene glycol were added to the experimental cuvette and the difference spectra were recorded. (A) (....-) $6.25 \mathrm{mM}$ v-CAP; (....) $18.75 \mathrm{mM}$ D-CAP. (B) (-...-) $6.6 \mathrm{mM}$ Tevenel; (....) $19.8 \mathrm{mM}$ Tevenel. 

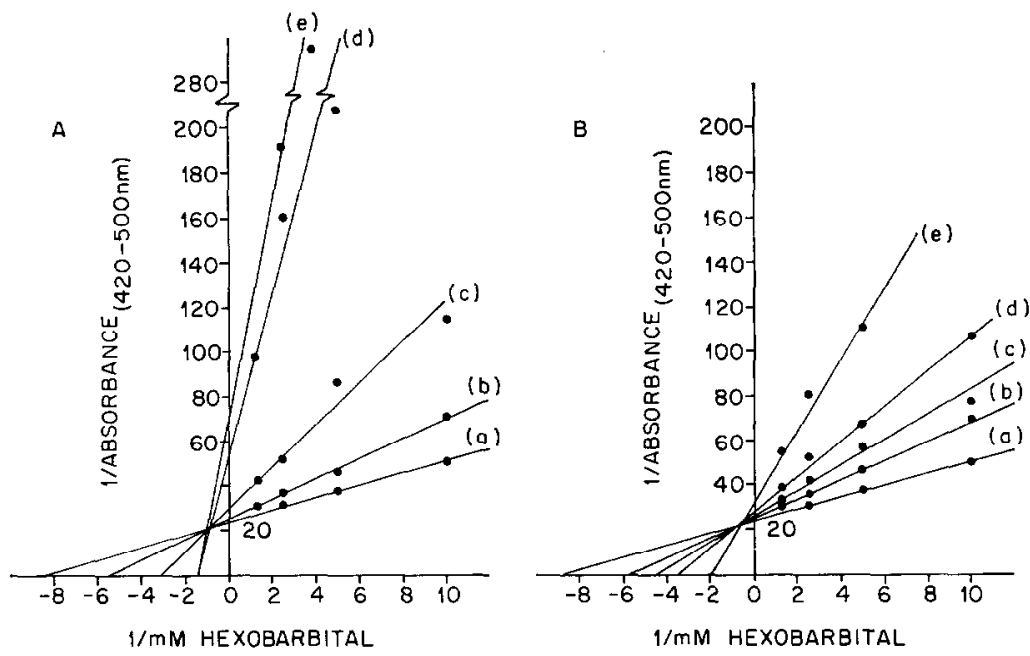

FIg. 5. The effect of D-CAP (A) and Tevenel (B) on titration of hexobarbital-induced Type I spectral changes. Liver microsomes were suspended in $0.2 \mathrm{M}$ sodium phosphate buffer, $\mathrm{pH} 7.5$, to a protein concentration of $2.6 \mathrm{mg} / \mathrm{ml}$ containing $2.4 \mu \mathrm{M}$ cytochrome P-450. D-CAP and Tevenel were suspended in propylene glycol. The difference spectra were recorded betwen 420 and $500 \mathrm{~nm}$. Line (a), no additions; line (b), propylene glycol; line (c), $0.25 \mathrm{mM}$ D-CAP or Tevenel; line (d), $1.25 \mathrm{mM}$ D-CAP or Tevenel; line (e), $5.0 \mathrm{mM}$ D-CAP or Tevenel.

D-CAP could decrease the rate of conversion of $\mathrm{CCl}_{4}$ to $\mathrm{CHCl}_{3} \cdot$ through inhibition or destruction of the $\mathrm{CCl}_{4}$-metabolizing system. This process would decrease the number of $\mathrm{CCl}_{3} \cdot$ molecules generated, and therefore the subsequent lipoperoxidative process and covalent binding of $\mathrm{CCl}_{4}$ metabolites to cellular proteins. Our evidence suggests that $\mathrm{D}-\mathrm{CAP}$ and its analogs bind to several sites on cytochrome $P-450$. Both D-CAP and Tevenel promote a reduction in the CO binding spectrum of cytochrome $P-450$, indicating a binding with the heme iron of cytochrome $P-450$. A Type I interaction can be detected in binding studies with hexobarbital by D-CAP and Tevenel. The ability of D-CAP to bind as a substrate is not unexpected, as Glazko (1966) has reported that D-CAP is metabolized by the liver. The noncompetitive inhibition exhibited by both D-CAP and Tevenel indicates interaction at a locus other than the substrate binding site. The difficulty one experiences in obtaining a conventional spectrum from incubating D-CAP and microsomes probably relates to the number of cytochrome $P-450$ sites on which D-CAP interacts. The significance of Tevenel interaction with cytochrome $P-450$ is paradoxical, as Tevencl is ineffective in ameliorating $\mathrm{CCl}_{4}$ hepatotoxicity. The mechanism of protection depends on a reaction that should be evident with D-CAP and absent with Tevenel. However, in binding studies Tevenel was less effective than D-CAP.

The locus of $\mathrm{CCl}_{4}$ activation is ill-defined. Some evidence argues that $\mathrm{CCl}_{4}$ activation occurs at cytochrome $P-450$. However, Slater and Sawyer (1971a, b) propose that the reduction of $\mathrm{CCl}_{4}$ occurs at the flavoprotein, cytochrome $P-450$ reductase. An alteration of the metabolism of $\mathrm{CCl}_{4}$ by $\mathrm{D}$-CAP could occur therefore through inhibition of this portion of the MFO system. Huyen et al. (1974) have reported a decline in reductase activity in the presence of D-CAP when 
assayed by the formation of a reduced cytochrome $P-450-\mathrm{CO}$ complex. However, when tested with cytochrome $c$ as an artificial electron acceptor, chloramphenicol did not alter reductase activity. The inhibition reported by Huyen $e$ t al. could be due to the binding of the heme iron by D-CAP. The possibility that D-CAP was decreasing $\mathrm{CCl}_{t}$ metabolism by causing a decrease in cytochrome $P-450$ levels was directly tested and ruled out, as D-CAP did not significantly alter cytochrome $P-450$ levels in a time interval consistent with the protective period.

Despite the reduction of lipid peroxidation by D-CAP, chloramphenicol did not prevent the loss of cytochrome $P-450$ associated with $\mathrm{CCl}_{4}$ intoxication as measured at 15 and $20 \mathrm{hr}$. Destruction of cytochrome $P$-450 did not coincide with the appearance of lipid peroxidation following administration of $\mathrm{CCl}_{4}$. For this reason, measurement of cytochrome $P-450$ was taken at a later stage of injury (15-20 hr) when cytochrome P-450 levels were substantially reduced. Ota et al. (1975) have suggested that $\mathrm{CCl}_{+}$irreversibly binds with cytochrome $P-450$, thus inhibiting MFO activity. D-CAP may lack the capacity to reverse this $\mathrm{CCl}_{4}$-cytochrome $P-450$ binding. Conversely, the loss of cytochrome $P-450$ during D-CAP inhibition of lipid peroxidation may simply reflect either the sensitivity of this enzyme to even the limited amount of lipid peroxidation that occurs in the presence of D-CAP or a delay in the degradative process. However, a delayed onset of lipid peroxidation is unlikely, as mitochondrial damage does not occur in the animal protected by D-CAP.

In light of D-CAP's amelioration of $\mathrm{CCl}_{4}$-induced mitochondrial damage, the diminished lipid peroxidation, and a reduction of mortality, the process responsible for necrotic development likely involves a peroxidative mechanism and mitochondrial damage. The above observations allow several routes for mitochondrial damage to be considered. (1) The process of lipid peroxidation could result in direct attack on mitochondrial membranes. (2) Mitochondrial damage may occur as a result of disruption of the ER, with a subsequent failure to synthesize mitochondrial components necessary for normal maintenance of homeostasis. Further delineation of these routes of mitochondrial damage are being attempted.

The results of this study suggest that chloramphenicol, a broad-spectrum antibiotic, prevents a lipoperoxidative process induced by $\mathrm{CCl}_{4}$ intoxication in vivo and inhibits an Fe-ADP-stimulated microsomal lipid peroxidation system in vitro. By determining the locus of the MFO system where D-CAP exerts its protective action, further insight into the etiology of $\mathrm{CCl}_{4}$-induced hepatonecrosis and other free radical-associated injury may be attained.

\section{ACKNOWLEDGMENTS}

The criticism and advice of Dr. I. A. Bernstein is gratefully recognized and appreciated by the authors. We also wish to express our appreciation to Mrs. Jeanne Clark for typing of the manuscript and Richard Hoyner and Marcie Skandis for technical assistance.

\section{REFERENCES}

Brabec, M. J., and Bernstein, I. A. (1975). Modulation of $\mathrm{CCl}_{4}$-induced liver damage by chloramphenicol. Fed. Proc. Amer. Soc. Exp. Biol. 34, 664.

Brabec, M. J., Bradley, C., and Bernstein, I. A. (1976). Studies on the antagonism by chloramphenicol of $\mathrm{CCl}_{4}$-induced damage: Examination of mitochondrial protein synthesis. Toxicol. Appl. Pharmacol. 38, 157-167. 
Castro, J. A., Diáz Gómez, M. I., de Castro, C. R., de Fenos, O. M., de Ferreyra, E. C., and D'Acosta, N. (1975). CCl induced polysome breakdown. Relative importance of lipid peroxidation and of binding to ribosomal components in the process. Res. Commun. Chem. Pathol. Pharmacol. 10, 93-104.

Dambrauskas, T., and Cornish, H. H. (1970). Effect of pretreatment of rats with carbon tetrachloride on tolerance development. Toxicol. Appl. Pharmacol. 17, 83-97.

Díáz Gómez, M. I., Castro, J. A., de Ferrera, E. C., D'Acosta, N. G., and de Castro, C. R. (1973). Irreversible binding of ${ }^{14} \mathrm{CCl}_{4}$ to liver microsomal lipids and proteins from rats pretreated with compounds altering microsomal mixed function oxygenase activity, Toxicol. Appl. Pharmacol. 25, 534-541.

Dixon, R. L., and Fouts, J. R. (1962). Inhibition of microsomal and metabolic pathways by chloramphenicol. Biochem. Pharmacol. 11, 715-720.

DUNNETT, C. W. (1955). A multiple comparison procedure for comparing several treatments with a control. J. Amer. Stat. Assoc. 50, 1096-1121.

Ernster, L., and Nordendrand, K. (1967). In "Methods in Enzymology" (R. W. Estabrook and M. E. Pullman, eds.), Vol. 10, pp. 574-580. Academic Press, New York.

GLAzKo, A. (1966). Identification of chloramphenicol metabolites and some factors affecting metabolic disposition. In "Anti-Microbial Agents and Chemotherapy-1966" (G. L. Hobby, ed.), 655-665. Amer. Microbiol., Ann Arbor.

Glende, E. A., JR. (1972a). CCl $_{4}$-induced protection against $\mathrm{CCl}_{4}$ toxicity: Role of the liver microsomal drug-metabolizing system. Biochem. Pharmacol. 21, 1697-1702.

GLENDE, E. A., JR. (1972b). On the mechanism of $\mathrm{CCl}_{4}$ toxicity-Coincidence of loss of drug metabolizing activity with peroxidation of microsomal lipid. Biochem. Pharmacol. 21, 2131-2138.

Glende, E. A., Jr., Hruszkewycz, A. M., and Recknagel, R. O. (1976). Critical role of lipid peroxidation in carbon tetrachloride-induced loss of aminopyrene dimethylase, cytochrome P-450 and glucose-6-phosphatase. Biochem. Pharmacol. 25, 2163-2170.

Gornall, A. G., Bardawill, C. J., and David, M. M. (1949). Determination of serum proteins by means of the biuret reaction. J. Biol. Chem. 177, 751-766.

Grogan, D. E., Lane, M., Smith, F. F., Bresnick, F., and Stone, K. (1972). Interaction of flavins and chloramphenicol with microsomal enzyme systems. Biochem. Pharmacol. 21, 3131-3144.

Hansch, C., Nakamoto, K., Gorin, M., Denisevich, P., Garrett, F. R., Heman-Ackah, S. M., and WoN, C. H. (1973). Structure-activity relationships of chloramphenicols. J. Med. Chem. 16, 917-922.

Huyen, H. I., and Banaschak, H. (1973). Schutzwirkung von chloramphenikol gegenüber tetrachlorkohlenstoff-intoxication bei der ratte. Acta Biol. Med. Germ. 31, K1-K6.

Huyen, H. I., Miller, D., Lübbe, H., and Klinger, W. (1974). Die Wirkung von chloramphenikol auf Bistransformationreaktionen. Arch. Int. Pharmacodyn. 211, 269-279.

OmuRa, T., and Sato, R. (1964). The carbon-monoxide-binding pigment of liver microsomes. I. Evidence for its hemoprotein nature. J. Biol. Chem. 239, 2370-2378.

OMura, T., and SATo, R. (1967). In "Methods of Enzymology" (R. W. Estabrook and M. E. Pullman, eds.), Vol. 10, pp. 556-565. Academic Press, New York.

Ota, M., Sato, N., Uemura, H., and Obara, K. (1975). Lowering effect of $\mathrm{CCl}_{4}$ on microsomal cytochrome P-450 of rat liver. Chem. Biol. Interact. 11, 265-276.

Recknagel, R. O. (1967). Carbon tetrachloride hepatotoxicity. Pharmacol. Rev. 19, 145-208.

RECKNAGEL, R. O., and Goshat, A. K. (1966). Quantitative estimation of peroxidative degeneration of rat liver microsomal and mitochondrial lipids after $\mathrm{CCl}_{1}$ poisoning. Exp. Mol. Pathol. 5, 413-426.

Schenkman, J. B., Remmer, H., and Estabrook, R. W. (1967). Spectral studies of drug interaction with hepatic microsnmal cytochrome. Mol. Pharmasol. 3, 113-123.

Schenkman, J. B., Cinti, D. L., Moldeus, P. W., and Orrenius, S. (1973). Newer aspects of substrate binding to cytochrome P-450, Drug Metab. Disp, 1, 111-120.

SEawright, A. A., and McLean, A. E. M. (1967). Effects of diet on $\mathrm{CCl}_{4}$ metabolism. Biochem. J. 105, 1055-1060.

Stater, T. F., and SAWYer, B. C. (1971a). The stimulatory effects of CCl and other halogenoalkanes on peroxidative reactions in rat liver fractions in vitro. General features of the system used. Biochem. J. 123, 805-814. 
SLATER, T. F., and SawYer, B. C. (1971b). The stimulatory effects of $\mathrm{CCl}_{4}$ on peroxidative reactions in rat liver fractions in vitro. Interaction sites in the ER. Biochem. J. 123, 815-821. SMuckLer, E. A., and HutTen, F. (1966). Effects of SKF 525-A and adrenalectomy on the amino acid incorporation by rat liver microsomes from normal and $\mathrm{CCl}_{4}$-treated rats. Exp. Mol. Pathol. 5, 504-515.

Steele, R. G. D., and Torrie, J. H. (1960.) In "Principles and Procedures in Statistics," pp. 99-132, 213-220. McGraw-Hill, New York.

Williams, C. H., and Kamin, H. (1962). Microsomal triphosphopyridine nucleotide-cytochrome $c$ reductase of liver. J. Biol. Chem. 237, 587-595. 